\title{
Tonsillotomy versus Tonsillectomy for Chronic Recurrent Tonsillitis in Children
}

\author{
Original Investigation \\ Yaser Said Çetin (1), Ufuk Düzenli (1) \\ Department of Otorhinolaryngology, Van Yüzüncü Yll University School of Medicine, Van, Turkey
}

\begin{abstract}
Objective: This study was conducted to compare two different surgical methods; partial tonsil resection using the bipolar technique, tonsillotomy (TT), and total tonsillectomy (TE) (blunt dissection) for recurrent tonsillitis in children. The frequency of recurrent throat infections was determined during postoperative follow-up.

Methods: A total of 393 patients were included in this study. TT was performed on 174 patients (100 males, 74 females) and TE on 219 patients (112 males, 107 females). Following surgery, an analysis was made of treatment outcomes of patients with upper respiratory tract infections. The patients were followed up for 12-48 months. Their parents were also contacted by telephone to determine the frequency of reinfection and their satisfaction with the surgery. Also, parents of the patients completed a questionnaire pertaining to postoperative satisfaction (scale of 1-10).
\end{abstract}

Results: In the TT group, 14 (8.1\%) patients had recurrent tonsillitis postoperatively. In the TE group, 12 (5.4\%) patients required antibiotherapy due to recurrent pharyngitis after the surgery. There was no significant difference between the two groups in terms of the one-year infection recurrence rate after surgery ( $p=0.281)$. Three patients $(1.6 \%)$ in the TT group and $12(5.4 \%)$ in the TE group complained of bleeding within the first 24 hours. The rate of bleeding was significantly lower in the TT group than the TE group $(p=0.001)$. There were no fatalities in either group.

Conclusion: In both groups, the rate of reinfection accorded with the requirement for postoperative antibiotics. For recurrent tonsillitis, TT was as effective as TE. However, TT was superior in terms of the risk of bleeding.

Keywords: Recurrent tonsillitis, tonsillotomy, tonsillectomy, bipolar tonsillotomy
ORCID IDs of the authors: Y.S.Ç. 0000-0002-7684-4600; U.D. $0000-0001-5603-5446$.

Cite this article as: Çetin YS, Düzenli U. Tonsillotomy versus Tonsillectomy for Chronic Recurrent Tonsillitis in Children. Turk Arch Otorhinolaryngol 2020; 58(1): 30-4.

\section{Corresponding Author:}

Yaser Said Çetin, dryasersaid@gmail.com

Received Date: 05.10.2019

Accepted Date: 08.01.2020

Content of this journal is licensed under a Creative Commons Attribution 4.0 International License. Available online at www.turkarchotolaryngol.net

\section{Introduction}

Tonsil surgery is one of the most common surgical interventions performed by ear, nose, and throat (ENT) specialists. However, differences between therapeutic techniques, including in terms of indications, are still under investigation. Although the number of cases indicated for surgery due to infection has decreased, a large proportion of cases still have an infectious origin $(1,2)$. Many cases of tonsillitis can be treated with antibiotics, but surgery is the first line treatment in patients with recurrent or chronic tonsillitis who do not respond to medical treatment. Various techniques have been applied in tonsil surgery. The disadvantage of the tonsillotomy (TT) technique is that the tonsils can regrow to serve as a source of infection. Therefore, many previous studies concluded that TT was not suitable for patients with chronic tonsillitis (3). The main advantage of the TT technique is the preservation of the tonsil capsule, which serves as a biological dressing, covering the pharyngeal muscles such that they are not directly exposed to trauma, or to inflammation arising from contact with saliva. Thus, both postoperative pain and healing time are reduced $(4,5)$. In general, ENT physicians prefer total tonsillectomy (TE) to TT for patients with frequent episodes of tonsillitis. In recent years, however, TT has been performed in patients with a history of frequent infections. But still, studies on the application of TT, which is a safe method for treating cases with frequent episodes of tonsillitis, are insufficient. The present study was performed 
to compare the frequency of postoperative upper respiratory tract infection in patients undergoing TE versus TT.

\section{Methods}

The study was carried out with approval from the Ethics Committee of Van Training and Research Hospital of the University of Health Sciences (approval number 2018/07, granted on December 4,2018). This retrospective cohort study reviewed the consecutive medical records of all children undergoing tonsil surgery at our tertiary center. In this study, 1,254 patients who underwent tonsillar surgery at our center from June 2014 through July 2018 were evaluated retrospectively in terms of surgical indications and approach. Only patients with chronic and/or recurrent tonsillar infection, and at least one year follow-up, were evaluated. A total of 393 patients were included in this study. The indications were determined according to Key Action Statement 2-3 of the current guidelines for TE in children (6). Patients with obstructive sleep apnea syndrome, continuous snoring, nasal congestion, abnormal dentofacial/orofacial development, recurrent/chronic adenoiditis, recurrent or chronic otitis media with effusion, recurrent or chronic sinusitis with adenoid hypertrophy, or suspicion of malignancy, were excluded from the study. Patients undergoing paracentesis and tube insertion were also excluded, along with those with immunodeficiency and hematological disorders or syndromes. Only patients who underwent surgery because of complaints of frequent tonsillitis were included in the study.

The patients were divided into two groups. The first group underwent general anesthesia for bipolar electrocautery (15 W),

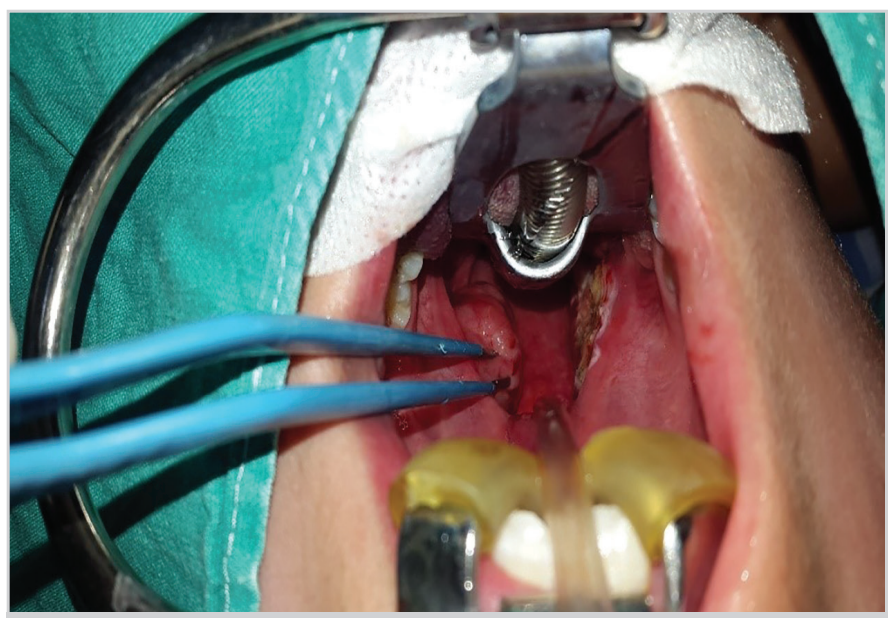

Figure 1. Bipolar electrocautery (15 W), tonsillotomy (TT), and bleeding control were applied in this case
TT and bleeding control. The tonsillar tissue was cauterized using bayonet nonbonding bipolar forceps. The ForceTriad Energy Platform (Medtronic-Covidien, Inc., Minneapolis, MN, USA) was used as a generator $(240 \mathrm{~V}, 50 \mathrm{~Hz})$. The cauterization power was fixed at $15 \mathrm{~W}$. TT was performed on the anterior plica line of each tonsil by cauterizing the surface several times. The full thickness of the tonsil was cauterized from the superior to the inferior direction, perpendicular to the level of the plica. The medial portion of the cauterized area was extracted by cutting with scissors (Figure 1).

The second group underwent cold dissection TE under general anesthesia with using sutures for the control of bleeding. We used vertical and horizontal sutures (4-0 braided absorbable polyglactin 910 sutures; Vicryl ${ }^{\oplus}$; Ethicon, Somerville, NJ, USA). During the postoperative period, patients with a diagnosis of recurrent throat infections were identified from among the electronic National Health Service hospital records. Patients who received antibiotic therapy at our center, or treatment for symptoms of upper respiratory tract infection from other physicians (especially pediatricians and family physicians), were identified from among the National Health Service data. After surgery, an analysis was made of the treatment outcomes of patients with upper respiratory tract infection. The patients were followed up for 12-48 months. During the same period, their parents were also contacted by telephone to determine the frequency of reinfection and their satisfaction with the surgery (Table 1). Patient's parents also completed a questionnaire pertaining to postoperative satisfaction (scale of 1-10).

\section{Statistical Analysis}

Descriptive statistics were used to analyze continuous (quantitative) variables. Data are expressed as the mean \pm standard deviation (SD). Categorical variables are expressed as numbers and percentages. The sample size required for each group was calculated with the Collins sampling calculation formula. For an estimated type 1 error rate of $5 \%(z=1.96)$ and power of $80 \%$, it was calculated that each group should consist of at least 123 patients. However, to increase the power, it was planned that each group would contain at least 174 patients. The independent $t$-test was used to compare the mean scores of the groups on parametric continuous variables. The chi-square test was used to analyze categorical variables. The z-ratio test was used to compare proportions. Minitab (version 17.0; Minitab Inc., State College, PA, USA) and the IBM Statistical Package for Social Sciences software for Windows version 24.0 (IBM SPSS Corp.;

Table 1. Patient characteristics: comparison between the tonsillotomy and tonsillectomy groups

How many times did your child undergo an upper respiratory tract infection that required antibiotics in the one year before surgery?

Does frequent firing continue?

How many times a year after the surgery has the patient been infected?

Has the patient been re-operated on for postoperative bleeding?

Has the patient been re-operated on because their complaints did not pass postoperatively?

Do you think the surgery achieved its purpose? A numerical ratio between 1 and 10 (yes=10, no=1)? 
Armonk, NY, USA) were used for the analyses, in all of which $\mathrm{p}<0.05$ was taken to indicate statistical significance.

\section{Results}

A total of 393 patients [212 males (53.9\%) and 181 females (46.1\%)] were included in this retrospective study. All patients were treated for chronic or recurrent tonsillitis. TT and TE were performed in 174 and 219 patients, respectively. The mean age of the patients undergoing TT for recurrent tonsillitis was 8.03 years (range: 4-15 years), while that of the patients undergoing TE was 7.4 years (range: $4-15$ years). The mean follow-up period was 24.84 months (range: $12-48$ months) in the TT group and 21.49 months (range: $12-48$ months) in the TE group.

In the TT group, the mean number of times antibiotic therapy was prescribed for recurrent tonsillitis per year was 5.89 preoperatively and 1.02 after surgery. Furthermore, 14 (8.1\%) TT group patients had frequent tonsillitis postoperatively, of whom four underwent reoperation (TE) because of frequent tonsillitis. The remaining 10 patients did not accept repeat surgery despite

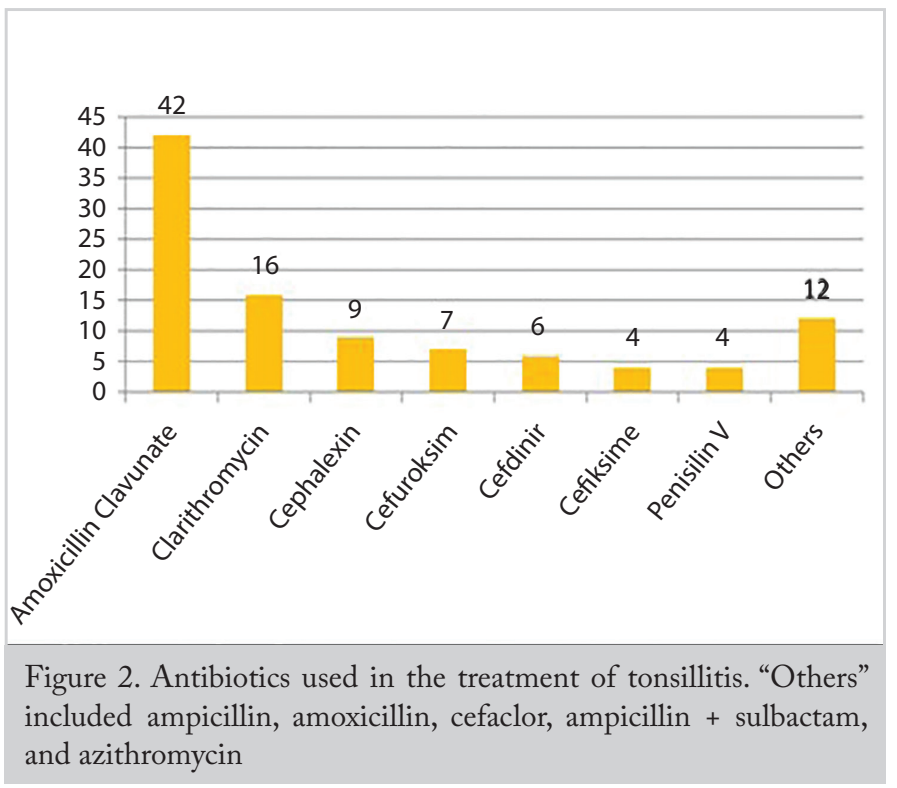

frequent tonsillitis; they had fewer tonsillitis episodes than preoperatively and preferred antibiotic therapy.

In the $\mathrm{TE}$ group, the mean number of times antibiotic therapy was prescribed for recurrent tonsillitis per year was 5.74 preoperatively, which decreased to 0.64 postoperatively. In the TE group, $12(5.4 \%)$ patients required antibiotic therapy due to recurrent pharyngitis after surgery. The antibiotics prescribed for patients diagnosed with tonsillitis or pharyngitis are shown in Figure 2 .

Three patients (1.6\%) in the TT group exhibited bleeding during the first 24 hours after surgery. In patients who presented with bleeding in the postoperative tonsillar region, the clots therein were cleared and treatment was provided in the form of a cold-water gargle and cotton impregnated with pantocaine-adrenaline. In one patient, bleeding continued despite treatment, so TE was performed under general anesthesia. In the remaining two patients, bleeding was self-limited by medical method. In the TE group, 12 patients (5.4\%) presented with bleeding. Eight of these patients were taken to the operating room and sutured again under general anesthesia. In the remaining four patients, bleeding was self-limited by medical methods. There were no fatal complications in either group. The rate of bleeding was significantly lower in the TT group than the TE group ( $p=0.001$, while there was no significant difference in mean postsurgical satisfaction evaluation score between the groups (Table 2).

\section{Discussion}

The indications, efficacy, necessity, risks, and benefits of tonsil surgery have been discussed in previous reports. Can TT replace TE in cases requiring tonsil surgery? The Paradise et al. (5) criteria for TE can be applied for assessment of clinical status and interpretation of examination results, and to guide the follow-up of patients scheduled for tonsil surgery. Patients with frequent tonsil infections should be evaluated clinically for up to one week for fever, painful cervical lymphadenopathy, and bacterial lymphadenopathy, which may indicate bacterial infec-

Table 2. Patient characteristics: comparison between the tonsillotomy and tonsillectomy groups

\begin{tabular}{|c|c|c|}
\hline & $\begin{array}{c}\text { Tonsillotomy group (TT), } \\
\mathrm{n}=174\end{array}$ & $\begin{array}{c}\text { Tonsillectomy group (TE) } \\
n=219\end{array}$ \\
\hline Gender (male/female) & $100 / 74$ & $112 / 107$ \\
\hline Age (years) & $8.03 \pm(2.53)$ & $7.4 \pm(2.73)$ \\
\hline Average follow-up period (months) & $24.84 \pm(10)$ & $21.49 \pm(9,9)$ \\
\hline Number of patients with postoperative bleeding (\%) & $3(1.6)$ & $12(5.4)$ \\
\hline Number of patients requiring surgery after postoperative bleeding & 1 & 8 \\
\hline Mean number of antibiotic prescriptions due to tonsillitis in the year before surgery & $5.89 \pm(1.14)$ & $5.74 \pm(1.15)$ \\
\hline Number of recurrent pharyngitis or tonsillitis episodes in the year after surgery (\%) & $14(8.1)$ & $12(5.4)$ \\
\hline Mean number of antibiotics prescriptions for tonsillitis or pharyngitis in the year after surgery & $1.02 \pm(1.58)$ & $0.64 \pm(0.97)$ \\
\hline Number of patients requiring revision surgery during follow-up & 4 & - \\
\hline Average family satisfaction score after surgery (scale of $1-10$ ) & $7.66 \pm(0.96)$ & $7.77 \pm(0.99)$ \\
\hline
\end{tabular}


tion such as group A beta-hemolytic streptococci (6). In one study, patients who experienced at least three tonsillitis episodes per year were divided into adenoidectomized, non-adenoidectomized and unoperated control groups. The three-year postoperative follow-up results showed a significantly lower incidence of throat infection in the patients treated with TE compared with those who did not undergo surgery. Elsewhere, TE was found to be effective in cases of recurrent infection $(5,7)$. Lemkens et al. (8) investigated whether TE affected the need for antibiotics by examining the medical records of patients in the one-year periods before and after TE. They reported that the mean preoperative antibiotic usage of the patients decreased from four boxes per year to one box per year. They also reported that the number of medical visits decreased from seven to four per year after TE.

Ericsson et al. (9) reported no significant differences in the rates of postoperative recurrent throat infections or antibiotic therapy use between patients treated with TT versus TE. Foki et al. (10) reported a reinfection rate of $9.8 \%$. TT has been found to be beneficial for patients with tonsillitis, by lowering the risk of recurrence compared with TE. Kim et al. (11) compared TT and $\mathrm{TE}$ in terms of the risk of recurrent infection, and recommended TT due to its association with lower postoperative pain intensity, a lower complication rate, a shorter recovery time, and lower cost. In the present study, the Paradise criteria were applied to cases of recurrent tonsillitis. Antibiotics were prescribed an average of 1.02 times in the year after recurrent throat infections in the TT group, versus 0.64 times in the TE group ( $\mathrm{p}=0.004)$. The rate of recurrent infection was $5.4 \%$ in the TE group and $8.1 \%$ in the TT group, which was not significantly different.

A retrospective study of TT and TE patients indicated that the proportion of patients requiring reoperation in the TT group $(17.5 \%)$ was seven times greater than that in the TE group (2.5\%). In that study, recurrent upper respiratory obstruction was found to be an important reason for reoperation, and there was no significant difference in the rate of reoperation between the TT and TE groups (12). In the present study, four (2.2\%) patients in the TT group underwent reoperation due to recurrent tonsillitis.

Bleeding has been reported at a rate of $0.1-20 \%$ after TE, with a mortality ratio due to bleeding of $1 / 1,000-1 / 170,000$. Some studies reported that postoperative bleeding was the most common cause of mortality following TE. Chronic or recurrent acute infections result in more bleeding due to destruction of the tonsil capsule and adhesion to the surrounding tissue (13, 14). Vicini et al. (15) compared TE and TT groups in terms of bleeding (a total of 450 cases). The rate of postoperative bleeding was $6.8 \%$ in the TE group and $0.7 \%$ in the TT group, and it was concluded that TT was safer and more effective than TE. In the present study, the rate of postoperative bleeding was $1.6 \%$ in the TT group and $5.4 \%$ in the TE group; again, indicating that TT was much safer than TE in terms of bleeding. However, one patient showed severe bleeding from the tonsillar tissue at the 12th hour after surgery. In this case, TE was performed. Bleeding resolved spontaneously in the other patients during follow-up. Thus, TT was safer than TE in terms of bleeding.
Previous studies reported satisfaction rates of $69-100 \%$ among the families of the children who underwent TE and adenotonsillectomy (16). Hoey et al. (17) performed a long-term follow-up study of 500 patients undergoing TT, which was used as an alternative to TE because of the ease of application and effective control of both obstructive and infective symptoms. The two surgical techniques showed similar efficacy and there was no significant difference in family satisfaction between the TE and TT groups.

Stasio et al. $(18,19)$ reported that the parents of pediatric patients expressed a preference for TE over TT. The need for further treatment, including of the possible long-term complications of TT and/or regrowth of tonsils, may lead to reoccurrence of streptococcal pharyngitis. In the present study, however, TT was found to be safe for treating recurrent tonsillitis in children.

Byars et al. (20) examined the data for 1.2 million children and found that the risk of infectious/parasitic and allergic diseases in children who underwent $\mathrm{TE}$ and adenoidectomy increased in later life, compared with those not subjected to such treatments. The tonsil and adenoids form part of the lymphatic system and are important in the normal development of the immune system. Therefore, long-term risks should be taken into consideration in the decision-making process regarding whether to perform $\mathrm{TE}$ or adenoidectomy.

This retrospective cohort study included children treated with one of two different surgical techniques for tonsil infections. A major limitation of this study was the absence of histological and bacteriological data.

\section{Conclusion}

All organs and tissues in the human body are crucial. We found that TT was safer than, and equally effective as, TE, and can therefore be recommended for the management of recurrent tonsillitis during childhood.

Ethics Committee Approval: Ethics committee approval was received for this study from the Ethics Committee of Van Training and Research Hospital of the University of Health Sciences (approval number 2018/07, granted on December 4, 2018).

Informed Consent: Informed consent was obtained from the parents of all participants included in the study.

Peer-review: Externally peer-reviewed.

Author Contributions: Concept - Y.S.Ç.; Design - Y.S.Ç.; Supervision - U.D.; Fundings - Y.S.Ç.; Materials - Y.S.Ç., U.D.; Data Collection and/or Processing - Y.S.Ç.; Analysis and/or Interpretation - U.D.; Writing - Y.S.Ç.; Critical Reviews - U.D.

Conflict of Interest: The authors have no conflicts of interest to declare.

Financial Disclosure: The authors declared that this study has received no financial support. 


\section{References}

1. Hallenstål N, Sunnergren O, Ericsson E, Hemlin C, Hessén Söderman A-C, Nerfeldt P, et al. Tonsil surgery in Sweden 2013-2015. Indications, surgical methods and patient-reported outcomes from the National Tonsil Surgery Register. Acta Otolaryngologica 2017; 137: 1096-103. [Crossref]

2. Ericsson E, Ledin T, Hultcrantz E. Long-term improvement of quality of life as a result of tonsillotomy (with radiofrequency technique) and tonsillectomy in youths. Laryngoscope 2007; 117: 1272-9. [Crossref]

3. Koltai PJ, Solares CA, Mascha EJ, Xu M. Intracapsular partial tonsillectomy for tonsillar hypertrophy in children. Laryngoscope 2002; 112: 17-9. [Crossref]

4. Kordeluk S, Goldbart A, Novack L, Kaplan DM, E1-Saied S, A1walidi $\mathrm{M}$, et al. Randomized study comparing inflammatory response after tonsillectomy versus tonsillotomy. Eur Arch Otorhinolaryngol 2016; 273: 3993-4001. [Crossref]

5. Paradise JL, Bluestone CD, Bachman RZ, Colborn DK, Bernard BS, Taylor FH, et al. Efficacy of tonsillectomy for recurrent throat infection in severely affected children-results of parallel randomized and nonrandomized clinical trials. N Eng J Med 1984; 310: 674-83. [Crossref]

6. Mitchell RB, Archer SM, Ishman SL, Rosenfeld RM, Coles S, Finestone SA, et al. Clinical practice guideline: Tonsillectomy in children (update). Otolaryngol Head Neck Surg 2019; 160: S1-S42. [Crossref]

7. Paradise JL, Bluestone CD, Colborn DK, Bernard BS, Rockette HE, Kurs-Lasky M. Tonsillectomy and adenotonsillectomy for recurrent throat infection in moderately affected children. Pediatrics 2002; 110: 7-15. [Crossref]

8. Lemkens N, Lemkens P, Egondi TW, Schrooten W, Jorissen M, Mertens $\mathrm{R}$, et al. Antibiotic use and doctor visits are reduced after adenotonsillectomy. B-ENT 2010; 6: 239-43.

9. Ericsson E, Graf J, Hultcrantz E. Pediatric tonsillotomy with radiofrequency technique: Long-term follow-up. Laryngoscope 2006; 116: 1851-7. [Crossref]

10. Foki E, Seemann R, Stelter K, Lill C. The effect of tonsillotomy on chronic recurrent tonsillitis in children. Acta Otolaryngol 2017; 137: 992-6. [Crossref]
11. Kim JS, Kwon SH, Lee EJ, Yoon YJ. Can intracapsular tonsillectomy be an alternative to classical tonsillectomy? A meta-analysis. Otolaryngol Head Neck Surg 2017; 157: 178-89. [Crossref]

12. Odhagen E, Sunnergren O, Hemlin C, Hessén-Söderman AC, Ericsson E, Stalfors J. Risk of reoperation after tonsillotomy versus tonsillectomy: A population-based cohort study. Eur Arch Otorhinolaryngol 2016; 273: 3263-8. [Crossref]

13. Lee HS, Yoon HY, Jin HJ, Hwang SH. The safety and efficacy of powered intracapsular tonsillectomy in children: A meta-analysis. Laryngoscope 2018; 128: 732-44. [Crossref]

14. Achar P, Sharma RK, De S, Donne AJ. Does primary indication for tonsillectomy influence post-tonsillectomy haemorrhage rates in children? Int J Pediatr Otorhinolaryngol 2015; 79: 24650. [Crossref]

15. Vicini C, Eesa M, Hendawy E, Pari M, D'Agostino G, AlGhamdi $\mathrm{S}$, et al. Powered intracapsular tonsillotomy vs. conventional extracapsular tonsillectomy for pediatric OSA: A retrospective study about efficacy, complications and quality of life. Int J Pediatr Otorhinolaryngol 2015; 79: 1106-10. [Crossref]

16. Wolfensberger M, Haury JA, Linder T. Parent satisfaction 1 year after adenotonsillectomy of their children. Int J Pediatr Otorhinolaryngol 2000; 56: 199-205. [Crossref]

17. Hoey AW, Foden NM, Hadjisymeou Andreou S, Noonan F, Chowdhury AK, Greig SR, et al. Coblation ${ }^{\circledR}$ intracapsular tonsillectomy (tonsillotomy) in children: A prospective study of 500 consecutive cases with long-term follow-up. Clin Otolaryngol 2017; 42: 1211-7. [Crossref]

18. Stasio SD, Yang C, Brietzke SE, Shah RK. Tonsillectomy versus tonsillotomy: A study of parental preference. Int J Pediatr Otorhinolaryngol 2015; 79: 359-62. [Crossref]

19. Stasio SD, Yang C, Brietzke SE, Shah RK. Response to letter to the editor for "tonsillectomy versus tonsillotomy: A study of parental preference". Int J Pediatr Otorhinolaryngol 2015; 79: 17901. [Crossref]

20. Byars SG, Stearns SC, Boomsma JJ. Association of long-term risk of respiratory, allergic, and infectious diseases with removal of adenoids and tonsils in childhood. JAMA Otolaryngol Head Neck Surg 2018; 144: 594-603. [Crossref] 